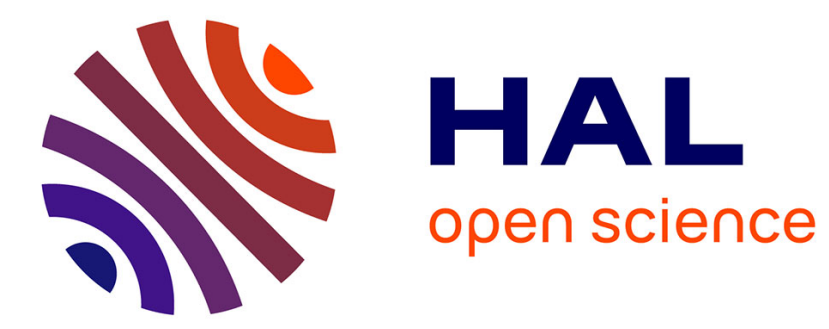

\title{
Efficient fast-recovery scheme for NMR pulse spectrometers
}

\author{
N.S. Sullivan, P. Deschamps, P. Néel, J.M. Vaissière
}

\section{To cite this version:}

N.S. Sullivan, P. Deschamps, P. Néel, J.M. Vaissière. Efficient fast-recovery scheme for NMR pulse spectrometers. Revue de Physique Appliquée, 1983, 18 (4), pp.253-261. 10.1051/rphysap:01983001804025300 . jpa-00245089

\section{HAL Id: jpa-00245089 https://hal.science/jpa-00245089}

Submitted on 1 Jan 1983

HAL is a multi-disciplinary open access archive for the deposit and dissemination of scientific research documents, whether they are published or not. The documents may come from teaching and research institutions in France or abroad, or from public or private research centers.
L'archive ouverte pluridisciplinaire HAL, est destinée au dépôt et à la diffusion de documents scientifiques de niveau recherche, publiés ou non, émanant des établissements d'enseignement et de recherche français ou étrangers, des laboratoires publics ou privés. 


\title{
Efficient fast-recovery scheme for NMR pulse spectrometers
}

\author{
N. S. Sullivan (*), P. Deschamps, P. Néel and J. M. Vaissière \\ Service de Physique du Solide et de Résonance Magnétique, \\ CEN Saclay, 91191 Gif sur Yvette Cedex, France
}

(Reçu le 23 novembre 1982, accepté le 23 décembre 1982)

\begin{abstract}
Résumé. - Nous décrivons un circuit utilisant une contre-réaction capacitive et un déphasage de $90^{\circ}$ pour réduire le temps mort des sondes RMN qui existe après une impulsion de radiofréquence. Le circuit d'amortissement fonctionne seulement pendant et pour un temps bref après l'impulsion, par conséquent l'efficacité et la sensibilité du spectromètre restent inchangées. Nous expliquons aussi l'utilisation d'un transistor à effet de champ à haute tension pour isoler le circuit de transmission de la sonde $R M N$ après l'impulsion. L'amortissement est très efficace pour les basses fréquences et nous avons pu réduire le temps mort d'un circuit de résonance en série $(Q=50)$ à moins de $7 \mu$ s à $3 \mathrm{MHz}$ avec cette technique.
\end{abstract}

\begin{abstract}
We describe an active damping circuit which uses a $90^{\circ}$ phase-shift feedback loop to dampen the ringing of nuclear resonance probes just after the RF excitation. The damping does not operate during the reception of the nuclear signal and there is therefore no loss in efficiency or in sensitivity as would be the case for permanent damping. The use of a high voltage FET as a gated duplexer to isolate the RF transmitter after the pulse is also described. The circuit damper is especially useful at low frequencies and we have been able to reduce the recovery time of a series resonant circuit $(Q=50)$ to less than $7 \mu \mathrm{s}$. at $3 \mathrm{MHz}$ using this feedback scheme and the gated duplexer.
\end{abstract}

1. Introduction. - The design of pulsed NMR receivers at low frequencies raises special problems if the signal to noise ratio is low and if large bandwidths are required as is often the case for NMR studies of solids. These problems arise from conflicting requirements which need to be met for an efficient yet fast recovery system :

i) an efficient conversion of RF power into a homogeneous oscillating magnetic field $H_{1}$ inside the NMR coil;

ii) a rapid build up and rapid decay of $H_{1}$ in order to be able to (a) determine the free induction decay (F.I.D.) origin accurately, and (b) observe weak signals as soon as possible after the RF pulse ;

iii) isolation of the receiver from the excitation in order to protect the receiver from saturation (e.g. charging of coupling capacitors);

iv) optimum reception of the nuclear signal along with efficient coupling of the nuclear resonance probe to the receiver.

(*) Present address : Department of Physics, University of Florida, Fl. 32611, U.S.A.
Requirement (ii) is in conflict with (i) and (iv) since efficient power conversion and reception require circuits with a high quality factor $Q\left(H_{1} \propto \sqrt{Q}\right.$ and $\mathrm{S} / \mathrm{N} \propto \sqrt{Q}$ ) while the natural ringing time

$$
\tau_{\mathrm{R}}=2 Q / \omega_{0},
$$

needs to be as short as possible. Typically, one must wait a « dead » time $\tau_{\mathrm{D}} \approx 20 \tau_{\mathrm{R}}$ for the circuit to ring down to noise level following a $1 \mathrm{kV}$ RF pulse. As an example, for a $Q \simeq 50, \tau_{\mathrm{R}}=5 \mu \mathrm{s}$ and $\tau_{\mathrm{D}} \simeq 100 \mu \mathrm{s}$ at $3 \mathrm{MHz}$.

We were faced with a particularly difficult problem, namely that of observing the ${ }^{1} \mathrm{H}$ F.I.D. signal of $\mathrm{CH}_{4}$ physisorbed on exfoliated graphite (with the view of studying the orientational ordering of $\mathrm{CH}_{4}$ on a triangular lattice). The ${ }^{1} \mathrm{H}$ resonance signal from $\mathrm{CH}_{4}$ was also exploited to optimize our NMR spectrometer prior to studies of physisorbed ${ }^{15} \mathrm{~N}_{2}$ which has a much weaker signal. Geometrical constraints on the sample size and eddy current dissipation in the graphite limited the $Q$-factor to approximately 50 (for which $\tau_{\mathrm{R}} \simeq 5 \mu \mathrm{s}$ and $\tau_{\mathrm{D}} \simeq 100 \mu \mathrm{s}$ ). This is twice the F.I.D. time scale for bulk methane (the first zero in the F.I.D. occurs at $37 \mu$ s for bulk $\mathrm{CH}_{4}$ in phase II below $20 \mathrm{~K}$ ). The apparent solution of carrying out the experiments 
at higher frequencies to reduce $\tau_{\mathrm{R}}$ is not always practical or desirable. For the graphite loaded sample chambers the loss in $Q$ at elevated frequencies and the attendant loss in $\mathbf{S} / \mathbf{N}$ and $R F$ conversion efficiency lead to an optimum operating frequency in the 4-7 $\mathrm{MHz}$ range. Quateman and Bretz $[1,2]$ report similar conclusions.

The operating frequency chosen for our studied was finally dictated by considerations of the weak ${ }^{15} \mathrm{~N}$ NMR signal from ${ }^{15} \mathrm{~N}_{2}$ physisorbed on graphite. In view of the field dependence of the ${ }^{15} \mathrm{~N}_{2}$ line shape due to the anisotropic chemical shift [3] in the orientationally ordered phase, a Larmor frequency of $3 \mathrm{MHz}$ corresponding to optimum contrast (i.e. sharp peaks in the asymmetrical Pake doublet line shape) was selected. This choice motivated the search for an efficient recovery scheme at low $\mathrm{RF}$ frequencies which did not unduly deteriorate the $\mathrm{S} / \mathrm{N}$ ratio.

The use of crossed coils [4-8] had to be excluded because of the impossibly difficult design problems associated with the employment of separate orthogonal transmitter and receiver coils in a tight cryogenic environment. Bridge circuits [7, 9-13] were also avoided because of their critical tuning conditions, relatively poor isolation and inherent $3 \mathrm{~dB}$ losses in $\mathrm{RF}$ transmission and reception. At high frequencies they do however offer a convenient solution for cryogenic applications [13]. Loose coupling schemes [14-16] also had to be rejected because of their poor matching and isolation features. The elegant high frequency delay line techniques of Lowe and collaborators [17-19] do provide extremely fast recoveries (at the expense of having very wide bandwidths) but they were not appropriate for our low frequency needs.

We were therefore led to consider : i) probe damping techniques for a large single NMR coil operating at low frequencies and ii) at the same time realize a receiver design that minimized the recovery time following the RF pulse without deterioration of the sensitivity. Many probe dampers (both active and passive) employed to dissipate the RF energy stored in the coil have been described in the litterature [5, 2031] but most suffer from two drawbacks.

Firstly, the removal of the damping circuit itself after the dissipation period causes the input circuit to ring anew, and secondly, only small improvements in the value of $\tau_{\mathrm{D}}$ are actually observed; e.g. at $4 \mathrm{MHz}$. Kisman and Armstrong [24] achieved a reduction in the dead time $\tau_{\mathrm{D}}$ by a factor of 8 in contrast to an anticipated improvement factor of 300 . Part of the difficulty is often due to the neglect of the receiver recovery following the ring-down and the ring-up of the damper. Consideration of the receiver recovery alone can lead to a substantial amelioration $[16,23$, 31-36] but the best approach is to consider the questions of probe damping and receiver recovery at the same time.

The problems discussed above are apparently circumvented by the use of a subtle damping circuit proposed by Hoult [29]. He used negative feedback to damper the nuclear resonance circuit permanently. The feedback is provided by a small capacitance and an amplifier which includes a $90^{\circ}$ phase shift. The effective input impedance due to the feedback therefore shunts the receiver input with a low resistance thereby lowering the effective $Q$. For Hoult's design at $5 \mathrm{MHz}$ with an unloaded $Q$ of 170 this reportedly led to no degradation of the noise performance and only a negligible change in the optimum bandwidth for maximum sensitivity. Our experience for lower frequencies $(2-4 \mathrm{MHz})$ and lower $Q_{\mathrm{s}}^{\prime}(\leqslant 50)$ was that permanent damping by this scheme always led to an appreciable loss of S/N (typically by a factor of 4 for a reduction of the dead time by a factor of 10 ). An improved technique therefore had to be sought for. Possible causes for this degradation of the sensitivity with permanent shunting by negative capacitive feedback at low frequencies are discussed in section 4.

The design solution that we reached for this problem was an active feedback circuit that provided damping just after the RF excitation; i.e. during the time it is needed most. This is described in the next section; the circuit analysis is given in section 3 and its performance is discussed in section 4.

2. Circuit design. - In order to maintain the RF voltage levels low at the spectrometer input and to facilitate the transfer of RF power to the NMR coil from a low impedance power amplifier, we used a series resonance configuration represented by $C_{\mathrm{S}}, L_{\mathrm{S}}$ and $r_{\mathrm{s}}$ of figure $1 . Q=\omega L_{\mathrm{S}} / r_{\mathrm{s}} \simeq 50$ and $r_{\mathrm{s}} \simeq 20 \Omega$. The output of the RF transmitter $\left(R_{0} \simeq 50 \Omega\right)$ is matched to the nuclear resonance circuit by the tuned coupling circuit $L_{\mathrm{c}}, C_{\mathrm{c}}$

$$
R_{0} r_{\mathrm{s}}=L_{\mathrm{c}} / C_{\mathrm{c}}=r_{\mathrm{S}}^{2}+\left(\omega L_{\mathrm{c}}\right)^{2} .
$$

$\left(L_{\mathrm{c}}=1.3 \mu \mathrm{H}, C_{\mathrm{c}}=1.2 \mathrm{nF}\right.$ for the circuit of Fig. 1). (As discussed below, the capacitance $2 C_{\mathrm{t}}$ resonates with the residual reactance at $\mathrm{X}$ during the $\mathrm{RF}$ pulse thereby minimizing the conductance in parallel with the probe circuit.)

The ringing time of the resonance coil $L_{\mathrm{S}}$ after the transmitted pulse is

$$
\tau_{\mathrm{R}}=\frac{2 L_{\mathrm{S}}}{R}
$$

where $R$ is the total series resistance through which current must pass to ground after the pulse is turned off. This resistance is made as large as possible by the use of an RF duplexer which transmits the RF pulse to the coil and disconnects the receiver during the transmission mode, whereas during the receiving mode the transmitter is disconnected and the receiver is connected. This has often been realized by the judicious use of passive crossed diode and quarterwavelength lines [21], but this has the disavantage that one must accept the relatively long ring-down of the voltage levels $(\approx \mathrm{kV})$ to the operating level $(\approx 0.5 \mathrm{~V})$ 


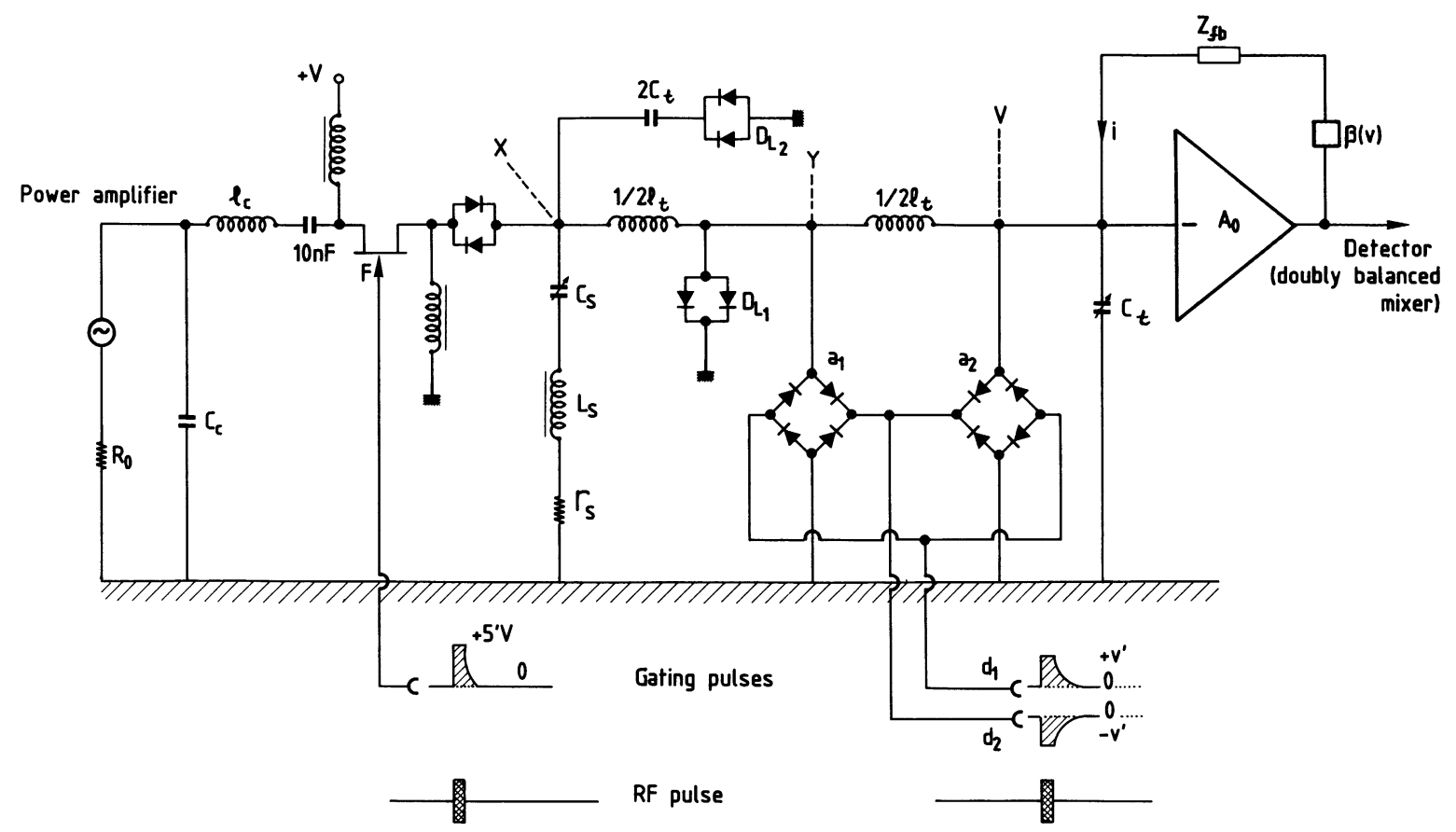

Fig. 1. - (a) Circuit diagram of pulse NMR spectrometer showing the active feedback loop - a crossed diode pair(IN4147) (which provides a $90^{\circ}$ phase shift at the required operating level) and feedback capacitance $C_{\mathrm{fb}}$ which serve to dampen the ringing of the input circuitry. The power amplifier is coupled to the nuclear resonance probe $\left(L_{\mathrm{S}}, R_{\mathrm{S}}\right)$ via the coupling circuit $\left(l_{\mathrm{c}}, C_{\mathrm{c}}\right)$. This coupling is opened after the RF pulse by the high voltage FET F (Motorola type MTP474). Diodes $\mathrm{D}_{\mathrm{L} 1}$ (four crossed diodes type FD700) damp the voltage level at $\mathrm{Y}$ to approximately $0.5 \mathrm{~V}$ and this is reduced to less than $1 \mathrm{mV}$ at $\mathrm{U}$ by the gated attenuators $\mathrm{a}_{1}$ and $\mathrm{a}_{2}$. (Hewlett-Packard matched quads HP82-2356.) $l_{\mathrm{t}} C_{\mathrm{t}}$ match the nuclear resonance circuit to the preamplifier input. (The blocking inductances for the FET are $100 \mu \mathrm{H}$.)

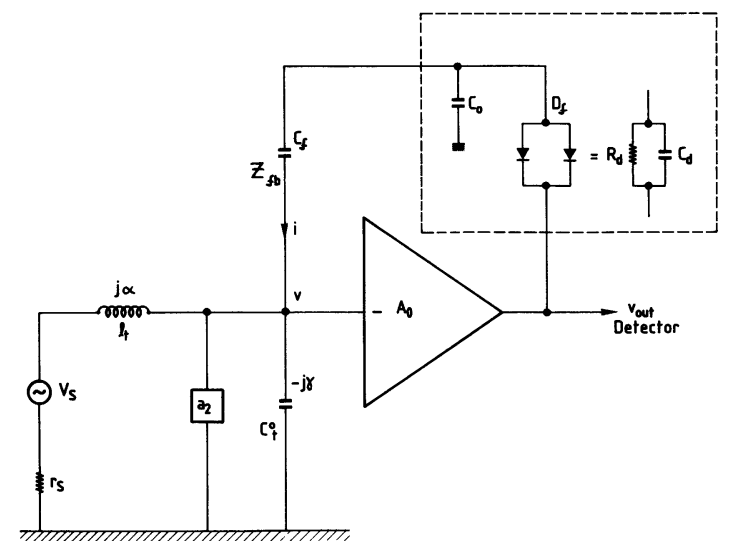

Fig. 1. - (b) Simplified schematic circuit diagram of the spectrometer.

of the diodes. We were able to improve on this delay with the use of an active duplexer. In order to withshand the high voltage levels during the break after the transmission mode and reduce feedthrough transients we used recently available high voltage field effect transistors (Motorala MTP 474) gated on by a logic pulse synchronous with the RF pulse width. The trailing edge of the gating pulse is shaped to have a $1 \mu$ s turn-off time in order to minimize the transients occurring after the gate is turned off.

During the transmission mode, the receiver is protected by the diode clamps $D_{L_{1}}$ and $D_{L_{2}}$ which conduct during the RF pulse. (Note that the matching coil $\frac{1}{2} l_{\mathrm{t}}$ in the coupling circuit to the receiver is tuned by the capacitance $2 C_{\mathrm{t}}$ during the transmission mode in order to maximize the resistance to ground at X.)

Use of the duplexer alone does provide a substantial improvement but we had to resort to active feedback damping to obtain total recovery times better than $35 \mu \mathrm{s}$. This is due to the need to speed-up the recovery of the diode clamps (ring-down from $0.5 \mathrm{~V}$ to noise level) and to compensate for the unavoidable contribution to the ring-down of the RF pulse due to leakage and stray capacitance in parallel with the NMR coil. (This is not a problem for parallel resonance circuits for which the stray capacitance just adds to the tuning capacitance, but for parallel tuning one does have very high RF voltage levels at the spectrometer head and stray pick-up by the receiver can then become a problem.) Before analysing the feedback circuit we will first describe the input circuit used to match the resonance circuit to the preamplifier during the receiving mode and the accompanying protection for the amplifier.

The low impedance $r_{\mathrm{S}}$ of the series resonant circuit is transformed to a high impedance by the transformation circuit $l_{\mathrm{t}} C_{\mathrm{r}}$. This is necessary since the noise figure for the wide band preamplifier is optimum for a source impedance $R_{\mathrm{S}} \simeq 50 \mathrm{k} \Omega$. In the present conditions $r_{\mathrm{S}} R_{\mathrm{IN}}=l_{\mathrm{t}} / C_{\mathrm{t}}$. In order to prevent damage and saturation of the preamplifier, diode limiters $D_{L}$ are used to limit the RF voltage level to approximately 
$0.5 \mathrm{~V}$ at $\mathrm{Y}$ during the $\mathrm{RF}$ pulse. This voltage is further reduced by the attenuator $a_{2}$ which is driven by logic pulses synchronous with the RF pulse. The balanced diodes (Hewlett-Packard HP82-2536) forming the ring circuits of $a_{1}$ and $a_{2}$ and the antisymmetric drives $d_{1}$ and $d_{2}$ assure minimum feedthrough at $U$. We found that for low frequencies, the low impedance of the diodes provides a more efficient attenuator than the use of the relatively high impedance low level FET'S despite the advantage of the reduced feedthrough of the latter.

During the gating pulse the diodes conduct $(r \sim 1 \Omega)$ and the voltage level of the order of $0.5 \mathrm{~V}$ at $\mathrm{Y}$ during the RF pulses is reduced to $\left(4 / \omega l_{\mathrm{t}}\right) \times 0.5 \simeq 0.5 \mathrm{mV}$ at point $U$. This level is sufficiently low to avoid saturation of the internal circuitry of the amplifier $\mathcal{A}_{0}$ (gain $\simeq 10^{3}$ ). Note that as for the power FET in the duplexer, the pulses $d_{1}$ and $d_{2}$ that drive attenuators $a_{1}$ and $a_{2}$ are shaped to have a sloping trailing edge in order to minimize the ring-up transients due to the attenuators themselves.

Although the amplifier is now well protected, a substantial reduction of the recovery time cannot be achieved if one uses a conventional amplifier to amplify the signal at $U$ following the RF pulse. Two serious problems remain. Firstly, the ring-up of the input circuit at $\mathrm{V}$ after the attenuators are switched off, lasts for approximately $10 \mu$ s and the total time for decay to noise level $(\simeq 10 \mu \mathrm{V})$ is approximately $40 \mu \mathrm{s}$. Secondly, the residual RF level of $0.5 \mathrm{mV}$ at the amplifier input during the pulse; while too low to saturate the amplifier, is amplified to about $0.5 \mathrm{~V}$ by $\mathcal{A}_{0}$. This leads to undesirably large levels for the synchronous detector (i.e. comparable to the carrier level of the doubly balanced mixer) which result in non-linear detection and interfere with the detection of weak nuclear resonance signals during the ringing time of the input circuity. This is illustrated in figure 2. (If the detection becomes non-linear one cannot circumvent the problem by the use of subtraction techniques, e.g. by recording $\mathrm{N}$ spectra on a signal averager with the $B$ field on-resonance and then subtracting $\mathbf{N}$ spectra with $\mathbf{B}$ off-resonance, since the F.I.D. signal during the initial part of the ringingtime will be non-linear. When the detection becomes linear $\left(t>\tau_{\mathrm{NL}}\right.$ in Fig. 2) this subtraction technique can be used to remove the unwanted background and obtain a useful signal for times significantly shorter than the time $\left(\tau_{\mathrm{D}}\right)$ needed for the ringing to decay to noise level.)

3. Feedback analysis. - The required improvement in recovery time at low frequencies was achieved by including crossed diodes $D_{f}$ in a capacitive feedback circuit with the operating conditions chosen so that the diodes conduct during the RF pulse and for a very brief period following the RF pulse. The circuit diagram is shown schematically in figure $1 b$ for the purposes of analysis. The diodes (type IN4147) are repre-

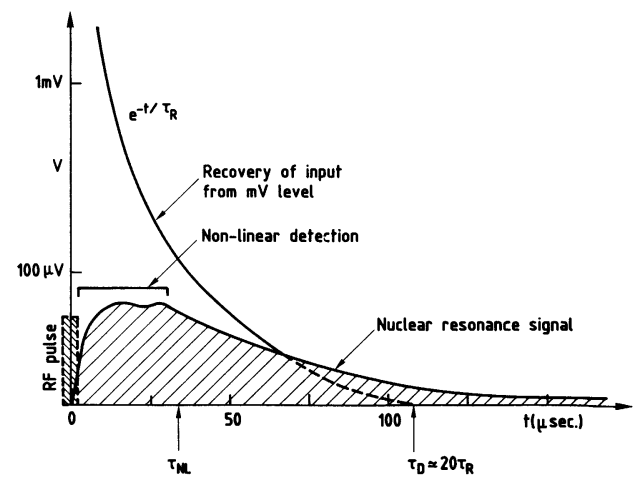

Fig. 2. - Recovery of the input circuity following an RF pulse after the attenuators $\left(a_{1}\right)$ and $\left(a_{2}\right)$ are turned off and when no active feedback is employed to speed-up the recovery time $(Q=50, f=3 \mathrm{MHz})$. Serious non-linear effects persist up to $\tau_{\mathrm{NL}} \simeq 35 \mu$ s while the amplifier output remains comparable to the carrier level of the detector. The rounding of the nuclear signal for very short times is due to the finite bandwidth determined by the $Q$-factor of the coil. The ringing remains above noise level for $\tau_{\mathrm{D}} \simeq 20 \tau_{\mathrm{R}} \simeq 100 \mu \mathrm{s}$ $\left(\tau_{R}=2 Q / \omega\right)$ and adds linearly to the nuclear signal for $t>\tau_{\mathrm{NL}}$. The nuclear signal can therefore be recovered for $t>\tau_{\mathrm{NL}}$ by subtracting the background observed for the magnetic field displaced off resonance.

sented by the parallel resistance-capacitance combination $R_{\mathrm{D}}-C_{\mathrm{D}}$.

Since $R_{\mathrm{D}}$ depends on the RF voltage level at the output of the amplifier $\mathcal{A}$, the diode impedance

$$
Z_{\mathrm{D}}=R_{\mathrm{d}} /\left[1+j \omega C_{\mathrm{d}} R_{\mathrm{d}}\right],
$$

and capacitance $C_{0}$ form a complex valued attenuator whose attenuation factor $\beta(v)$ depends on the voltage level $v$.

$$
\beta(v)=\left(1+j \omega C_{\mathrm{d}} R_{\mathrm{d}}\right) /\left(1+j \omega\left(C_{0}+C_{\mathrm{d}}\right) R_{\mathrm{d}}\right) .
$$

The impedance at the amplifier input is

$$
Z_{\text {in }}=z_{\mathrm{fb}} /\left[1-\mathcal{A}^{\prime}\right]
$$

where $z_{\mathrm{fb}}=1 / j \omega C_{\mathrm{f}}$ is the feedback impedance and $\mathcal{A}^{\prime}=\mathcal{A}_{0} \cdot \beta(v) . \mathcal{A}_{0}$ is the amplifier gain. The design of the amplifier shown in figure $3 a$ employs a broadband integrated circuit (RCA type CA3102E) driven by the low noise high impedance cascade J-FET input stage. The gain as a function of frequency is given in figure $3 b$ and the amplifier was carefully tested to ensure that a $180^{\circ}$ phase shift occurred at the operating frequency. (The inductive elements in the collector circuits of the I.C. are chosen to compensate the phase lag at the high frequency limit of the band.) For $\mathcal{A}_{0}$ large and negative we have

$$
Z_{\text {in }}=z_{\mathrm{fb}} /\left|\mathcal{A}_{0}\right| \cdot \beta(v) .
$$

If $\beta$ is real, then $Z_{\text {in }}$ is capacitive,

$$
C_{\text {in }}=\left|\mathcal{A}_{0}\right| \cdot \beta C_{\mathrm{f}} .
$$




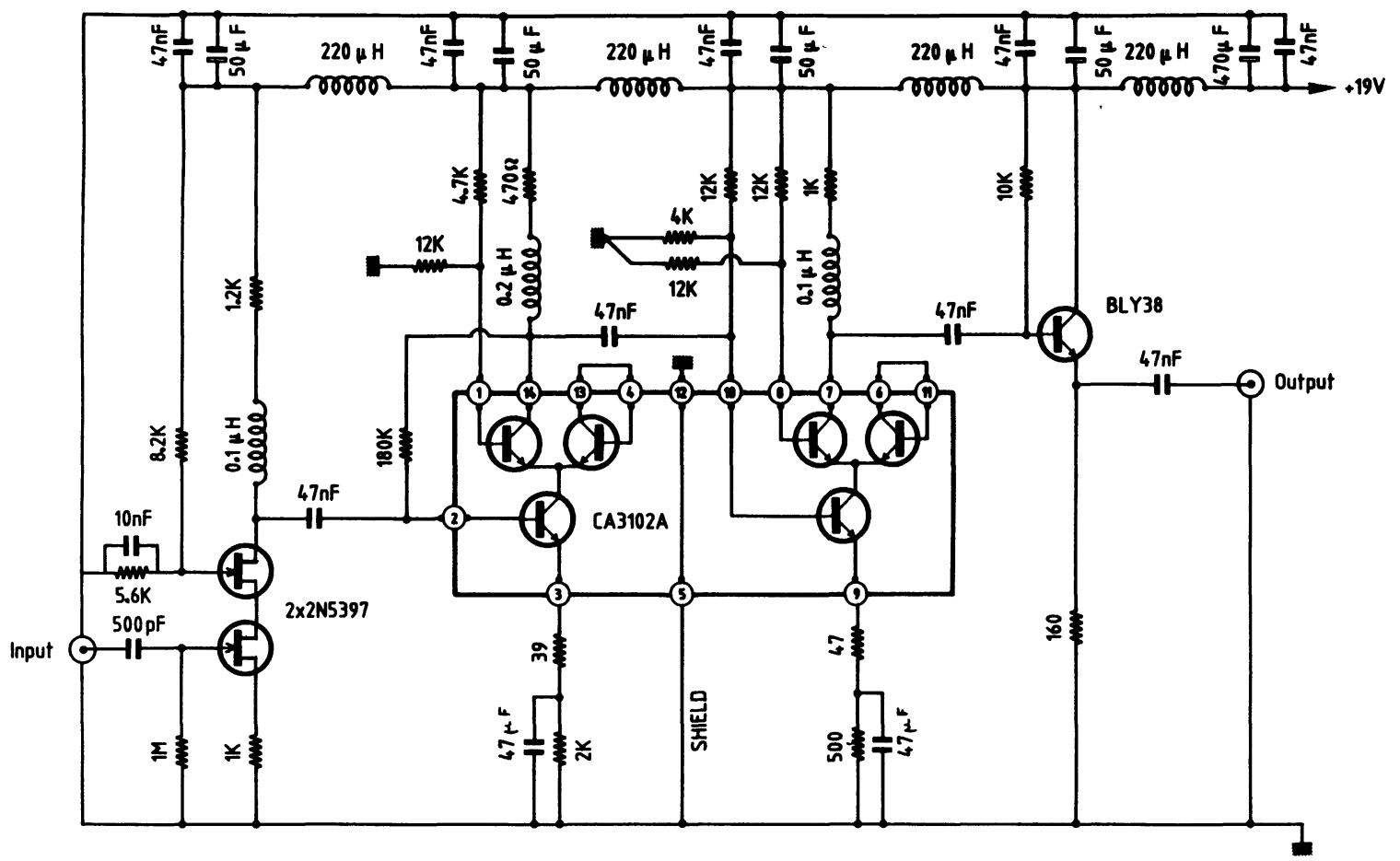

Fig. 3. - (a) Circuit diagram of the low noise broadband preamplifier used for the spectrometer. The input uses an FET cascade pair $T_{1}$ and $T_{2}$ (siliconix type $2 \mathrm{~N} 5397$ ) to drive the broadband integrated circuit array (R.C.A. type CA3102E). The output transistor (R.T.C. type BLY38) is used as an emitter follower to drive a $50 \Omega$ load.

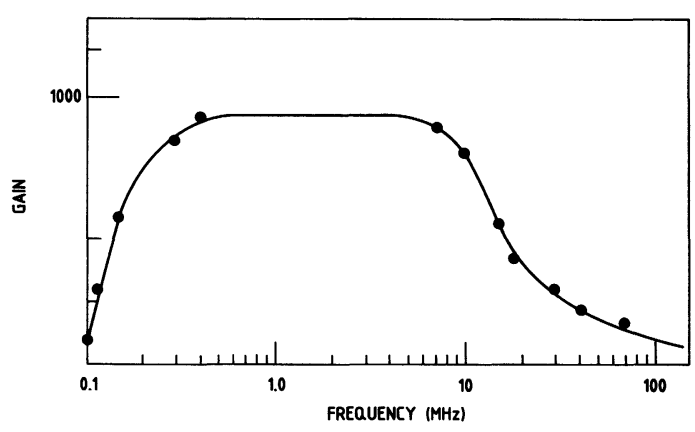

Fig. 3. $-(b)$ Observed bandwidth of the preamplifier given in figure $3 a$.

This is the Miller effect. If on the other hand $\beta$ is negative imaginary, the input impedance is real and low

$$
R_{\mathrm{IN}}=\left[\left|\mathcal{A}_{0}\right| \cdot|\beta| \omega C_{\mathrm{f}}\right]^{-1} .
$$

This can be typically a few ohms which is ideal for damping the input during the recovery time; the energy being absorbed by the amplifier.

This condition is realized in practice by choosing $C_{0}$ and the RF levels at the output (via selection of the gain of $\mathcal{A}_{0}$ ) so that $\beta(v)$ becomes imaginary just for those RF levels for which we need to accelerate the recovery time. In order to understand the operation and design criteria we will now analyse the overall operation of the receiver with feedback for different levels.

We consider the schematic circuit of figure $1 b$. The voltage source $\mathrm{V}_{\mathrm{s}}$ designates the nuclear signal from the series resonance circuit $L_{\mathrm{s}} C_{\mathrm{S}} r_{\mathrm{s}}$. As discussed above the transformation circuit $l_{\mathrm{t}} C_{\mathrm{t}}$ matches the low series resistance $r_{\mathrm{S}}$ to the amplifier input $\left(R_{\mathrm{IN}} r_{\mathrm{S}}=\right.$ $\left.l_{\mathrm{t}} / C_{\mathrm{t}}\right)$ and the diode attenuators $\mathrm{a}_{1}$ and $\mathrm{a}_{2}$ driven synchronously with the RF pulse limit the voltage $v$ at the amplifier input to less than $1 \mathrm{mV}$. ( $a_{1}$ holds the voltage at $\mathrm{Y}$ in Fig. $1 a$ to less than $1 \mathrm{~V}$ and $\mathrm{a}_{2}$ reduces this to below $1 \mathrm{mV}$ at the input to allow the feedback circuit to be operative during the RF pulse and prevent paralysis from excess input levels.)

For the purpose of analysis the input impedance of $\mathcal{A}_{0}$ (approximately $50 \mathrm{k} \Omega$ ) is included as a small imaginary contribution to $C_{\mathrm{t}}$. We define

$$
\gamma^{-1}=\omega C_{\mathrm{t}}^{0}+1 / j R_{\mathrm{IN}} \text {. }
$$

Similarly, the source resistance $r_{\mathrm{S}}$ can be included in $\alpha$ (see Fig. 1b)

$$
\alpha=\alpha_{0}-j \mathbf{r}_{\mathbf{s}} .
$$

Summing the currents at the amplifier input we find for the voltage level at $U$ :

$$
v=V_{\mathrm{S}}\left\{1-\alpha\left[\gamma^{-1} \div j\left(\mathcal{A}_{0}-1\right) z_{\mathrm{fb}}^{-1}\right]\right\},
$$

and as output level

$$
v_{\text {out }}=\mathcal{A}_{0} V_{\mathrm{S}} /\left[1-\alpha\left(\gamma^{-1}+\left(\mathcal{A}_{0}-1\right) \omega C_{\mathrm{f}}\right)\right] .
$$

The operation of the feedback circuit can now be described in terms of three regimes according to the RF levels that exist at the amplifier input as the RF pulse dies away : 
A) the initial ringing after the RF power pulse during which the protective diode clamps are conducting,

B) during the ring-down of the voltage at $U$ from a few $\mathrm{mV}$ to noise level,

and $\mathrm{C}$ ) the detection of the nuclear resonance signal.

Regime A. - During the RF pulse, the amplifier output is maintained at about $0.5 \mathrm{~V}$ and the diodes conduct with $R_{\mathrm{d}} \simeq 1-10 \Omega$. $\beta(v) \simeq 1$ (real) and the feedback circuit simply adds an equivalent capacitance $\left|\mathcal{A}_{0}\right| C_{\mathrm{f}}$ in parallel with $C_{\mathrm{t}}^{0}$ which pulls the input circuit off resonance and helps reduce the input voltage.

Since the attenuator $\mathrm{a}_{2}$ is on, $r_{\mathrm{a}_{2}} \simeq 1 \Omega$ and consequently

$$
-j \gamma \simeq r_{\mathrm{a}} \simeq 1,
$$

$\alpha=\frac{1}{2} \omega l_{\mathrm{t}}$ and we have $\alpha / \gamma=2000 j$ with $\alpha \omega C_{\mathrm{f}}=$ $\frac{1}{2} \omega^{2} l_{\mathrm{t}} C_{\mathrm{f}} \simeq 10^{-2}$. Hence, from equation (7) we have

$$
v_{\text {out }} \simeq-\frac{1}{2} j V_{\mathrm{L}}
$$

where $V_{\mathrm{L}}$ is the drop across the diode limiters $\mathrm{D}_{\mathrm{L}}$. The important point here is that for the circuit parameters described, if the diodes $D_{L}$ are on, then the diodes in the feedback loop are at the threshold of conducting. This is the optimum condition for a smooth transition to the second regime.

Regime B. - During the ring-down of the voltage at $\bar{Y}$ and the ring-up at $\mathrm{V}$, the diodes $\mathrm{D}_{\mathrm{L}}$ are no longer limiting; $V_{\mathrm{L}}$ at $\mathrm{Y}$ drops and $v_{\text {out }}$ falls accordingly. $R_{\mathrm{D}}$ therefore increases rapidly from a few ohms (for $v_{\text {out }} \sim 500 \mathrm{mV}$ ) to a few $\mathrm{k} \Omega$ (for $v_{\text {out }} \simeq 200 \mathrm{mV}$ ). During this stage the diode loop and $C_{0}$ now behave as a complex valued attenuator.

From equation (2) above for $\beta(v)$ we have

$$
\beta(v)=1 /\left[1+j \omega C_{0} R_{\mathrm{d}}\right],
$$

as long as

$$
R_{\mathrm{d}}(v)<\frac{1}{\omega C_{\mathrm{d}}} \simeq 10^{4} \Omega .
$$

For $R_{\mathrm{d}}(v)>1 / \omega C_{0} \simeq 10^{3} \Omega$; i.e. for $0.05 \lessgtr v_{\text {out }} \lesssim$ $0.40 \mathrm{~V}$ we therefore have

$$
\beta(v)=\frac{1}{j \omega C_{0} R_{\mathrm{d}}},
$$

and a $90^{\circ}$ phase shift in the feedback loop is realized. As long as the attenuator remains on this has little effect since in this case

$$
|\alpha / \gamma|>\left|\alpha \omega C_{\mathrm{f}}\right|,
$$

and from equation (7)

$$
v_{\text {out }} \simeq \frac{1}{2} \text { as in regime } \mathrm{A} .
$$

There is therefore no violent transition to regime $B$ if the attenuator is held conducting by a suitably adjusted trailing edge for the gate pulses $d_{1}$ and $d_{2}$. This is determined empirically.

Regime B, properly speaking, comes into being when the attenuator $a_{2}$ is turned off. We now have

$$
\left.\alpha / \gamma=\sqrt{\left(r_{\mathrm{S}} / R_{\mathrm{IN}}\right)}\right)
$$

which is typically $2 \times 10^{-2}$ and much less than $\alpha A \omega C_{f}$ in equation (7) for the output voltage level

$$
\begin{aligned}
v_{\text {out }} & =-V_{\mathrm{s}} /\left(\alpha \omega C_{\mathrm{f}}\right) \\
& =-V_{\mathrm{s}}\left(C_{\mathrm{t}}^{0} / C_{\mathrm{f}}\right),
\end{aligned}
$$

as expected if one could neglect the real part of the input impedance.

The additional input impedance due to the feedback loop is

$$
\begin{aligned}
Z_{\mathrm{IN}} & =z_{\mathrm{fb}} /\left|\mathcal{A}_{0}\right| \cdot \beta(v) \\
& =\left[j \omega \beta(v) C_{\mathrm{f}}\left|\mathcal{A}_{0}\right|\right]^{-1} .
\end{aligned}
$$

As long as the $90^{\circ}$ phase shift condition

$$
\beta(v)=\frac{1}{j \omega C_{0} R_{\mathrm{d}}},
$$

is maintained (i.e. for $50 \lesssim v_{\text {out }} \lesssim 400 \mathrm{mV}$ for a pair of IN4147 diodes at $3 \mathrm{MHz}$ ) the input impedance is real and low :

$$
Z_{\mathrm{IN}} \simeq \frac{1}{\left|\mathcal{A}_{0}\right|} \cdot \frac{C_{0}}{C_{\mathrm{f}}} \cdot R_{\mathrm{d}}
$$

thus adding a shunting resistance of 30-100 $\Omega$ to the input. The voltage $V_{\mathrm{L}}$ across $\mathrm{D}_{\mathrm{L}}$ therefore decays rapidly with time constant

$$
\tau_{\mathrm{B}} \simeq R_{\mathrm{IN}} C_{\mathrm{t}}^{0} \simeq 0.2 \mu \mathrm{s} .
$$

A factor of $e^{-4}\left(4 \tau_{\mathrm{B}} \simeq 0.8 \mu \mathrm{s}\right)$ suffices to drop $v_{\text {out }}$ to the noise level $\left(v_{\text {out }} \simeq 10 \mathrm{mV}\right)$ and for these levels

and

$$
\begin{aligned}
R_{\mathrm{d}} & >10^{5}, \\
C_{0} R_{\mathrm{d}} & \gg 1, \\
C_{\mathrm{d}} R_{\mathrm{d}} & \simeq 1,
\end{aligned}
$$

$$
\beta=C_{\mathrm{d}} / C_{0} \simeq 2 \times 10^{-2} \text {. }
$$

The input impedance is once again real and the damping present in phase B is removed. We are now ready to discuss the detection regime $(C)$.

Regime C. - As explained above $\beta=C_{\mathrm{d}} / C_{0}$ in this regime but $\alpha$ now takes the steady state value $\alpha=\omega l_{\mathrm{t}}-j r_{\mathrm{s}}$ and $l_{\mathrm{t}}$ is chosen to resonate with the total input capacitance at $U$. The purely capacitance

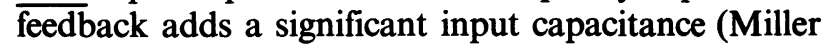


effect) to the tuning capacitance $C_{\mathrm{t}}^{0}$ and the resonance condition for the transformation circuit becomes

$$
\begin{aligned}
1 & =\operatorname{Re}\left\{\alpha\left[\gamma^{-1}-(A-1) j z_{\mathrm{fb}}^{-1}\right]\right\} \\
& =\left(\omega l_{\mathrm{t}}\right)\left\{\omega C_{\mathrm{t}}^{0}+(\mathcal{A}-1) \omega C_{\mathrm{f}}\right\}-r_{\mathrm{S}} R_{\mathrm{IN}}^{-1} \\
& =\omega^{2} l_{\mathrm{t}} C_{\mathrm{t}}^{\mathrm{tot}}-r_{\mathrm{S}} R_{\mathrm{IN}}^{-1} .
\end{aligned}
$$

The latter term is negligible and

$$
C_{\mathrm{t}}^{\mathrm{tot}}=C_{\mathrm{t}}^{0}+(\mathcal{A}-1) C_{\mathrm{f}} .
$$

Expressing the voltage $v$ as $v=V_{\mathrm{s}} / \varepsilon$ we find

$$
\begin{aligned}
\varepsilon & =1-\alpha\left[\gamma^{-1}-(\mathcal{A}-1) z_{\mathrm{fb}}^{-1}\right] \\
& =\frac{\omega l_{\mathrm{t}}}{R_{\mathrm{IN}}}\left\{1+r_{\mathrm{S}} R_{\mathrm{IN}} C_{\mathrm{t}}^{\mathrm{tot}} / l_{\mathrm{t}}\right\} \\
& =\frac{2 \omega l_{\mathrm{t}}}{R_{\mathrm{IN}}}=2 Q_{\mathrm{t}}^{-1}
\end{aligned}
$$

since the elements of the transformation circuit are chosen to satisfy $R_{\mathrm{IN}} r_{\mathrm{S}}=l_{\mathrm{t}} / C_{\mathrm{t}}^{\text {tot }} \cdot Q_{\mathrm{t}}$ defines an operational quality factor for the complete circuit (within the approximations used here).

4. Performance. - The expected performance following the analysis given above is portrayed in figure $4 a$. This is to be compared with the observed

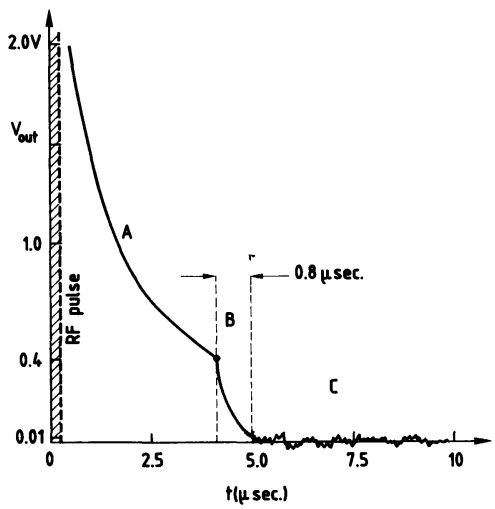

Fig. 4. - (a) Schematic representation of the recovery of the overall circuit of figure 1 according to the three regimes determined by the RF level. (A) : ring-down of the initial level to the operating level of the diode clamps, (B) : rapid damping of the input circuit during the operation of the $90^{\circ}$ phase shift provided by the diodes in the feedback loop, (C) : operation with the diodes in the feedback circuit off. During regime $(C)$ the damping circuit is inoperative and one benefits from full sensitivity.

recoveries at the amplifier input shown in figures $4 b$ and $4 c$. The rapid damping of the ring-down when the $90^{\circ}$ phase shift comes into operation is clearly visible. The decay to the operating level of the diode clamps (regime A) is now the determing factor for the total recovery time. As shown in figure $4 c$, this in turn is considerably improved with the use of the FET to open the coupling between the transmitter and the probe after the RF pulse. The residual ringing seen

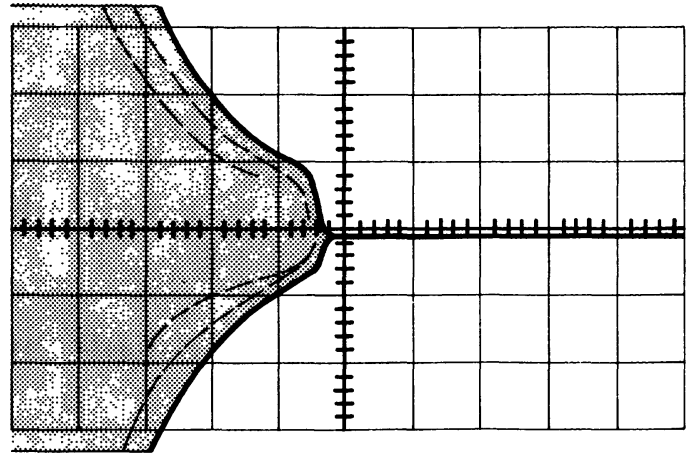

Fig. 4. - (b) Oscillogram showing the observed recovery $(Q=50, \mathrm{f}=3 \mathrm{MHz})$ at the amplifier input without the use of the power FET duplexer. Vertical scale $200 \mathrm{mV} /$ div., horizontal scale $2 \mu \mathrm{s} /$ div. The three distinct operating regimes of figure $4 a$ are clearly visible.

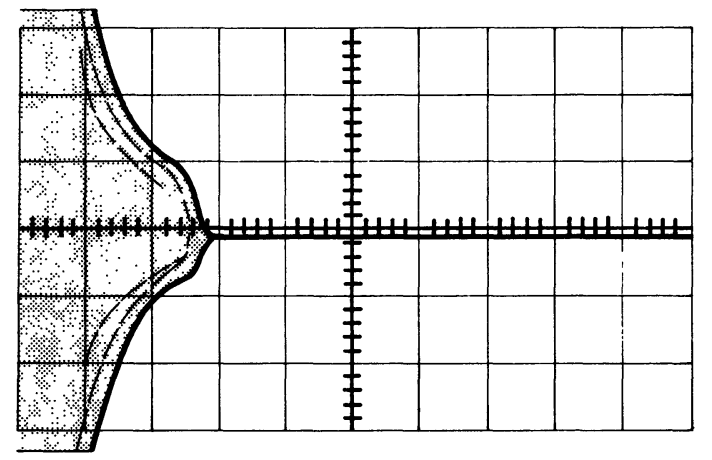

Fig. 4. - (c) Oscillogram as for (b) but with the use of the power FET to isolate the transmitter after the RF pulse. The residual ringing during regime (A) is due largely to stray capacitances in parallel with the probe. The total dead time is approximately $5.8 \mu \mathrm{s}$ for these relatively high levels at the input to the amplifier. (The response for weak signals detected at the output is shown in Figs. 5.)

in figure $4 c$ is due to stray capacities paths (BNC connectors, short cable lengths...) in parallel with the resonance coil $L_{s}$. (This ringing occurs at a much higher frequency than the natural resonance frequency of the probe circuit and further improvement can be gained by including an additional filter in the input and/or narrow-banding the amplifier.)

In order to illustrate the overall performance, two practical examples are shown in figures $5 a$ and $5 b$. The difficult case of the weak ${ }^{1} \mathrm{H}$ signals from physisorbed methane at $2.9 \mathrm{MHz}$ is shown in figure $5 a$. The recovery time is approximately $7 \mu$ s after the edge of the RF excitation pulse. The signal in figure $5 a$ represents the accumulation of 1024 F.I.D.'s using a Nicolet 1170 signal averager with a $500 \mathrm{MHz}$ input bandwidth. The observed signal to noise ratio of 45 is only a factor $2.4(1.9 \mathrm{~dB})$ below the ideal theoretical [31] signal/noise for one monolayer of $\mathrm{CH}_{4}$. The noise figure of the broadband preamplifier was assessed at $1.3 \mathrm{~dB}$ showing that additional losses due to the cryogenic cable and the detector must be includ- 


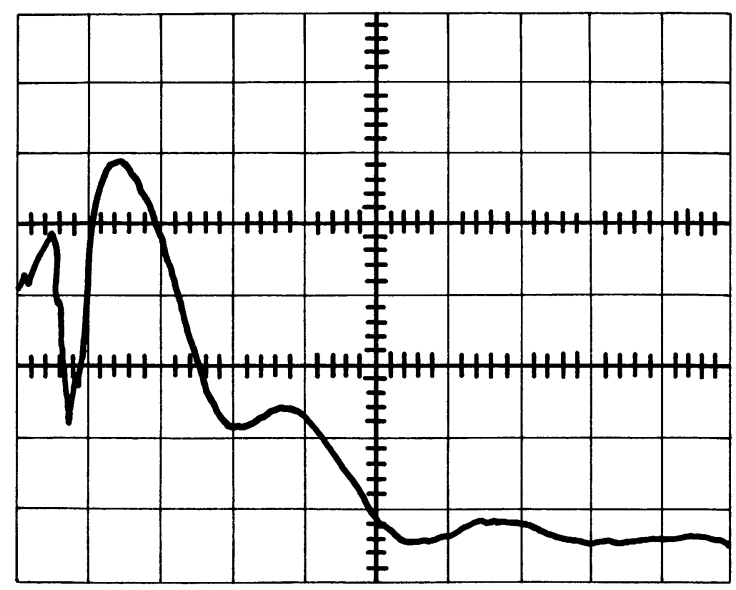

Fig. 5. - (a) ${ }^{1} \mathrm{H}$ F.I.D. from one monolayer of $\mathrm{CH}_{4}$ physisorbed on exfoliated graphite. (Larmor frequency 2.9 $\mathrm{MHz}, T=4.8 \mathrm{~K}$.) The signal shown represents the average of 1024 accumulated F.I.D.'s. (As a result of magnetic impurities in the graphite the F.I.D. shown is shorter than the natural decay of pure $\mathrm{CH}_{4}$.) Horizontal scale $10 \mu \mathrm{s} /$ div.

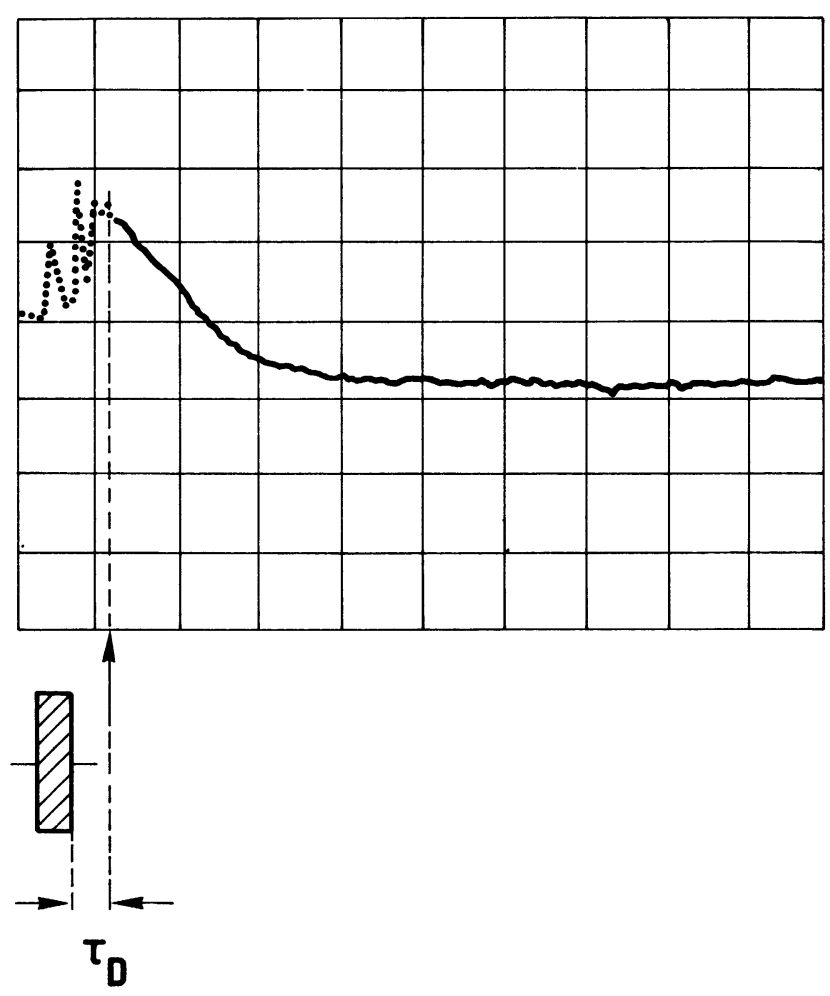

Fig. 5. - (b) ${ }^{1}$ H F.I.D. from solid hydrogen (45\% ortho concentration, $T=0.22 \mathrm{~K}$ ) at $25 \mathrm{MHz}$. Horizontal scale $5 \mu \mathrm{s} /$ div. Vertical scale $50 \mathrm{mV} /$ div.

ed $\left(F_{\text {add. }}^{\text {est. }} \simeq 0.6 \mathrm{~dB}\right)$ to account for the observed sensitivity.

The oscillogram of figure $5 b$ is a one shot record of the F.I.D. signal from solid hydrogen $(45 \%$ ortho concentration, $T=0.22 \mathrm{~K}$ ) at $25 \mathrm{MHz}$ for a $Q$-factor of approximately 35 . Complete recovery following a $0.6 \mu \mathrm{s}$ RF pulse occurs within $2.0 \mu \mathrm{s}$. This example serves to emphasize the interest that one has to work at high frequencies when it is feasible to do so.
The use of the active feedback network and the FET duplexer leads to a reduction of the dead time $\left(\tau_{\mathrm{D}} \simeq\right.$ $110 \mu \mathrm{s})$ of the bare circuit by a factor of approximately 15 at the lowest frequency studied (2.9 MHz). This represents an appreciable improvement with respect to previously published techniques that do not resort to permanent damping of the NMR coil (e.g. Kisman and Armstrong [24] report a reduction of $\tau_{\mathbf{D}}$ by a factor of 8 at $4.3 \mathrm{MHz}$ using a PIN diode damper and $\lambda / 4$ - lines for duplexing action).

While the permanent damping scheme of Hoult [29] does reportedly lead to slighter better improvements, we observed a substantial degradation in noise performance at $3 \mathrm{MHz}$ with his technique. This is to be expected since permanent feedback always increases the noise for a linear amplifier even if the feedback components are purely reactive [31]. If the power spectra $\omega_{\mathrm{i}}$ associated with the equivalent current noise source of the amplifier is expressed as [31] $\omega_{\mathrm{i}}=4 k T g_{\mathrm{n}}$, the optimum noise temperature is increased by the factor $\sqrt{\left(1+|g| / g_{n}\right)}$ where $g$ is the feedback admittance. Attributing $\omega_{\mathrm{i}}$ to the FET cascade input of our pramplifier, we estimate

$$
g_{\mathrm{n}}=\frac{1}{4} g_{\mathrm{m}}\left(f / f_{\mathrm{T}}\right)^{2} \simeq 2 \times 10^{-7} \Omega^{-1},
$$

where $f_{\mathrm{T}}=g_{\mathrm{m}} / 2 \pi C_{\mathrm{gd}}$ is the " cut-off " frequency of the 2N5397 and $g_{\mathrm{m}}$ its transconductance. $C_{\mathrm{gd}}$ is the grid-drain capacitance. For typical values of $g$, this alone indicates an increase in noise temperature by a factor of almost 5. Hoult's elegant scheme is therefore not recommended for those applications where sensitivity is of prime importance.

5. Conclusion. - The active damping circuit described here which shunts the ringing circuit just after the RF pulse excitation provides a very efficient yet straightforward means of improving the recovery time (or dead time) of NMR pulse spectrometers at low frequencies. A reduction of the dead time by a factor of 15 (with respect to the natural recovery time of the NMR circuit) was realized at $3 \mathrm{MHz}$ and this could be improved by careful lay-out techniques and by taking precautions to minimize stray leakages and feedback paths shunting the NMR coil. These leakages are responsible for at least $4.5 \mu$ s of the observed $7 \mu$ s dead time at $3 \mathrm{MHz}$. The circuit is very versatile and could be easily adopted for most spectrometers (large or narrow band) by including a variable attenuator in the feedback path. This is then set to assure that the diodes in the feedback circuit open and provide the required additional $90^{\circ}$ phase shift for resistive damping at the desired output level of the spectrometer.

Acknowledgments. - It is a pleasure to thank Michel Devoret, Daniel Estève and Stanislas Leibler , for many helpful discussions concerning the operation 
and improvement of pulse NMR spectrometers. We are also indebted to Jean-Marc Delrieu for many pertinent comments concerning the problems of stray RF pick-up and leakage. We are grateful to Hans Glättli and Francis Williams for their critical reading of the manuscript and many useful suggestions.

\section{References}

[1] Quateman, J. H. and Bretz, M., Phys. Rev., to be published.

[2] Quateman, J. H., Ph. D. Thesis, University of Michigan, 1982 (unpublished).

[3] Scott, T. A., Physics Reports 27 (1976) 89.

[4] Mansfield, P. and Powles, J. G., J. Sci. Instr. 40 (1963) 232.

[5] Clark, W. G., Rev. Sci. Instr. 35 (1964) 316.

[6] Jones, G. P., Douglas, D. C. and MC Call, D. W., Rev. Sci. Instr. 36 (1965) 1460.

[7] SpoKas, J. J., Rev. Sci. Instr. 36 (1965) 1436.

[8] Samuelson, G. L. and Allion, D., Rev. Sci. Instr. 42 (1970) 1329.

[9] Lowe, I. J. and BarnaAl, D. E., Rev. Sci. Instr. 34 (1963) 143.

[10] Jeffrey, K. R. and Armstrong, R. L., Rev. Sci. Instr. 38 (1967) 634.

[11] Klein, M. P. and Phelps, D. E., Rev. Sci. Instr. 38 (1967) 1545.

[12] Moores, B. M. and Armstrong, R. L., Rev. Sci. Instr. 42 (1971) 1329.

[13] Sullivan, N. S. and Pound, R. V., Cryogenics (1972).

[14] Trappeniers, N. J., Gernitsman, C. J. and OAsTING, P. J., Physica 30 (1964) 997.

[15] Gray, K. W., Hardy, W. N. and Noble, J. D., Rev. Sci. Instr. 37 (1966) 587.

[16] MC KAY, R. A. and WOESSNER, D. E., J. Sci. Instr. 43 (1966) 838.

[17] Lowe, I. J. and TARr, C. E., J. Phys. EI (1968) 320.

[18] Lowe, I. J. and EngelSberg, M., Rev. Sci. Instr. 45 (1974) 631.

[19] Lowe, I. J. and Whitson, D. N., Rev. Sci. Instr. 48 (1977) 268.
[20] Roeder, S. B. W., Rhodes, N. L. and Schmidt, G. W., Rev. Sci. Instr. 42 (1970) 1692.

[21] Ellett JR., J. D., Gibby, M. G., Haeberlen, V., Huber, L. M., Mehring, M., Pines, A. and Waugh, J. S., Advances in Magnetic Resonance (Academic Press, New York) Volume 5, 1971.

[22] Granell, P. K., Orchard, M. J., Mansfield, P., Garroway, A. N. and Stalher, D. C., J. Phys. E 6 (1973) 1202.

[23] Clark, W. G. and Mc Neil, J. A., Rev. Sci. Instr. 44 (1973) 844.

[24] Kisman, K. E. and Armstrong, R. L., Rev. Sci. Instr. 45 (1974) 1159.

[25] Garroway, A. N. and Ware, D., Rev. Sci. Instr. 46 (1975) 1342.

[26] ConRadi, M. S., Rev. Sci. Instr. 46 (1975) 1342.

[27] ENGLe, J. L., Rev. Sci. Instr. 49 (1978) 1356.

[28] Hoult, D. I., Rev. Sci. Instr. 50 (1979) 193.

[29] WoOd, B. M. and CODE, R. F., Rev. Sci. Instr. 52 (1981) 386.

[30] Robinson, F. N. H., Noise and Fluctuations in Electronic Devices and Circuits (Clarendon Press, Oxford) 1974.

[31] Ramadan, B., Ny, T. C. and Tward, E., Rev. Sci. Instr. 45 (1974) 1174.

[32] Schreiber, L. B. and Vaughan, R. W., J. Catal. 40 (1975) 226.

[33] Aducci, D. J., Hornung, P. A. and Torgeson, D. R., Rev. Sci. Instr. 47 (1976) 1503.

[34] Stokes, H. T., Rev. Sci. Instr. 49 (1978) 1011.

[35] Stoll, M. E., Rev. Sci. Instr. 52 (1981) 391. 